\title{
SINTESIS SENYAWA 4-HIDROKSI-3-METOKSI-5-(FENILDIAZENIL) BENZALDEHIDA DAN UJI AKTIFITAS ANTIOKSIDANNYA TERHADAP DPPH
}

\author{
A. Ghanaim Fasya, A. Hanapi, Riza Ayu Putri Ningseh \\ Jurusan Kimia, Fakultas Sains dan Teknologi, UIN Maulana Malik Ibrahim Malang
}

\begin{abstract}
Some of natural materials, such as vanillin, sinamaldehide and eugenol, are very potential as starting materian in synthesis of long conjugated system compounds wich can use as antioxidants, sun block active compounds and acid-base indicators. This research aims are were to know the result of 4-hydroxy-3-methoxy-5(phenyldiazenil) benzaldehide compound and to know it's antioxidant activity to DPPH. Synthesis of 4-hydroxy3-methoxy-5-(phenyldiazenil) benzaldehide was done by react benzenadiazonium chloride salt with vanillin at temperature $0-5^{\circ} \mathrm{C}$. The result purity was tested by determine it's melting point and the antioxdidant activity was determine at concentration of $25,50,100,200$, and $500 \mathrm{ppm}$. The research result showed that coupling diazo reaction between vanillin and benzenaiazonium ion resulted brown-black solid with melting point of $100{ }^{\circ} \mathrm{C}$ and rendemen of $88.54 \%$ that indicated as 4-hydroxy-3-methoxy-5-(phenyldiazenil) benzaldehide compound. Antioxidant activity of the result was not strong enough because of the purity, so need to be purified and separated.
\end{abstract}

Keywords : Vanilin, diazo coupling, antioxidant, DPPH.

\begin{abstract}
ABSTRAK
Beberapa bahan alam seperti vanilin, sinamaldehida dan eugenol sangat berpotensi sebagai bahan dasar sintesis senyawa dengan sistem terkonjugasi panjang yang dapat dimanfaatkan sebagai antioksidan, bahan aktif tabir surya dan indikator titrasi asam-basa. Penelitian ini bertujuan untuk mengetahui hasil sintesis senyawa 4hidroksi-3-metoksi-5-(fenildiazenil) serta mengetahui aktivitas antioksidan dari senyawa 4-hidroksi-3-metoksi-5(fenildiazenil) benzaldehida terhadap DPPH. Sintesis senyawa yang memiliki aktivitas antioksidan dilakukan dengan pembuatan garam benzenadiazonium klorida. Garam benzenadiazonium selanjutnya direaksikan dengan vanilin pada suhu $0-5{ }^{\circ} \mathrm{C}$. Senyawa hasil sintesis diuji kemurniannya dengan mengukur titik lelehnya. Uji aktivitas antioksidan terhadap DPPH dengan variasi konsentrasi (K) yaitu: 25, 50, 100, 200, dan 500 ppm. Reaksi kopling diazo antara senyawa vanilin dengan ion benzenadiazonium menghasilkan senyawa 4-hidroksi-3metoksi-5-(fenildiazenil)benzaldehida yang masih belum murni. Senyawa produk sintesis berupa padatan berwarna coklat kehitaman dengan rendemen $88,54 \%$ dan titik lebur $100^{\circ} \mathrm{C}$. Senyawa hasil sintesis memiliki aktivitas antioksidan. Aktivitas antioksidan senyawa hasil sintesis masih tergolong sangat lemah karena masih berupa campuran dan masih memerlukan proses optimalisasi dan pemisahan.
\end{abstract}

Kata kunci : Vanilin, kopling diazo, antioksidan, DPPH

\section{PENDAHULUAN}

Tumbuhan vanilla merupakan tumbuhan yang banyak dibudidayakan di Indonesia. Tumbuhan vanilla mengandung senyawa fenolik berupa vanilin yang memiliki aktivitas antioksidan. Hal ini sebagai salah satu nikmat yang diberikan Allah SWT kepada manusia. Manusia patut mengingat akan kekuasaan Allah dengan bersyukur, mempelajari dan memanfaatkan sebaik-baiknya apa yang 101 telah diberikan Allah kepada kita. Allah berfirman dalam surat asy Syu'araa' ayat 7

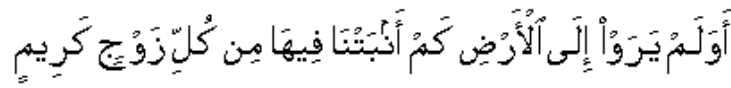

$$
\begin{aligned}
& \text { "Dan apakah mereka tidak } \\
& \text { memperhatikan bumi, berapakah } \\
& \text { banyaknya Kami tumbuhkan di bumi itu } \\
& \text { berbagai macam pasangan (tumbuh- } \\
& \text { tumbuhan) yang baik?" (QS. asy } \\
& \text { Syu'araa':7). }
\end{aligned}
$$


Firman Allah dalam surat asy Syu'araa' ayat 7 tersebut terdapat kata إلَّى yang mengandung makna batas akhir yang berfungsi memperluas arah pandangan hingga batas akhir. Perluasan arah pandang ini mengundang manusia untuk mengarahkan pandangannya hingga batas kemampuannya, dengan aneka tanah dan aneka keajaiban yang terhampar pada tumbuh-tumbuhan. Kata زَوْنج berarti pasangan. Pasangan yang dimaksud ayat ini adalah tumbuh-tumbuhan. Hal ini mengisyaratkan bahwa tumbuh-tumbuhan memiliki pasangan (benang sari dan putik) guna pertumbuhan dan perkembangannya serta kesetabilannya. Kata كرَيٍْ juga digunakan untuk menggambarkan segala sesuatu yang baik bagi objek yang disifatinya. Menurut Shihab (2002), tumbuhan yang baik dalam hal ini adalah tumbuhan yang bermanfaat bagi makhluk hidup.

Mengacu pada penelitian yang dilakukan oleh Shyamala dkk. (2007), melaporkan bahwa untuk menetralkan radikal bebas dibutuhkan vanilin dengan konsentrasi yang tinggi. Modifikasi struktur vanilin perlu dilakukan agar kemampuan antioksidannya meningkat, misalnya dengan memperpanjang sistem terkonjugasi dari vanilin.

Menurut penelitian Naik (2012), mekanisme pembentukan senyawa 4metoksi-2-asetilbenzofuran melibatkan, $o$ alkylation o-vanillin dengan asam kloro asetat dengan adanya DBU sebagai basa organik dilengkapi o-alkylated salicyaldehyde yang kemudian menghasilkan anion enolat melalui reaksi cyclocondensation intramolekul. Senyawa hasil sintesisini memberikan aktivitas antioksidan yang tinggi sebesar $9 \pm 0,14$ dibandingkan dengan o-alkylation $o$ vanillin $(61 \pm 0,24)$, asam kloro asetat ( $64 \pm$ 0,21), $\operatorname{DBU}(25 \pm 0,52), \quad$ o-alkylated salicyaldehyde $(13 \pm 0,93)$, anion enolat (15 $\pm 0,11$ ) dan juga lebih dari standar (BHA) $12 \pm 0,10$.Hal ini menunjukkan bahwa senyawa dengan ikatan rangkap terkonjugasi memberi potensi aktivitas antioksidan yang tinggi. Radikal bebas yang terbentuk dari senyawa yang memiliki aktivitas antioksidan inicenderung stabil oleh penataan ulang molekul diena terkonjugasi (Jadhav dkk., 1996).

Penelitian Purwono dkk. (2013) menghasilkan senyawa 4-hidroksi-3metoksi-5-(fenildiazenil)-benzaldehida

melalui reaksi antara vanilin dan garam benzenadiazonium dengan perbandingan mol yang sama. Namun nilai rendemen yang didapat relatif rendah yaitu 37,04\%, dari sisa vanilin berdasarkan data GC masih cukup besar. Peningkatkan nilai rendemen dapat diperoleh dari perbandingan mol reaktan, misalnya membuat mol garam benzenadiazonium klorida yang lebih tinggi dibanding mol vanilin.

Oleh karenanya, dalam penelitian ini akan disintesis senyawa turunan vanilin dengan memanfaatkan posisi orto dari gugus $-\mathrm{OH}$ pada vanilin. Menurut penelitian Purwono dkk. (2013), subtituen berupa ion benzene diazonium akan terikat pada posisi orto melalui reaksi kopling diazo menghasilkan turunan senyawa azo yaitu 4-hidroksi-3-metoksi-5(fenildiazenil)benzaldehida sebagai indikator titrasi asam basa dengan rendemen $37,04 \%$. Gugus azo $(\mathrm{N}=\mathrm{N})$ akan memperpanjang delokalisasi elektron keluar cincin aromatis sehingga diharapkan senyawa hasil sintesis ini akan memiliki aktivitas sebagai antioksidan yang lebih tinggi dari vanilin.

Penelitian ini bertujuan untuk mensintesis senyawa 4-hidroksi-3-metoksi5-(fenildiazenil) dan mengetahui aktivitas antioksidannya terhadap DPPH.

\section{METODE PENELITIAN}

Penelitian ini akan dilaksanakan pada bulan Mei - Oktober 2014 di Laboratorium Kimia Organik Jurusan 
Kimia Universitas Islam Negeri (UIN) Maulana Malik Ibrahim Malang.

\section{Alat dan Bahan}

Alat yang digunakan dalam penelitian ini adalah seperangkat alat gelas, neraca analitik, penangas es, termometer, rotary evaporator, desikator, inkubator, alat penentu titik lebur, spektrofotometer UVVis, spektrofotometer IR, spektrometer GC-MSdan ${ }^{1} \mathrm{H}-\mathrm{NMR}$.

Bahan yang digunakan dalam penelitian ini adalah vanilin p.a (Merck), anilina p.a (Merck), HCL $37 \%$ b/v p.a (Merck), $\mathrm{NaOH}$ p.a (Merck), $\mathrm{NaNO}_{2}$ p.a (Merck), $\mathrm{CHCl}_{3}$ p.a (Merck), $\mathrm{NaHCO}_{3}$ p.a (Merck), $\mathrm{Na}_{2} \mathrm{SO}_{4}$ anhidrat, p.a (Merck), akuades, etanol dan larutan DPPH.

\section{Rancangan Penelitian}

Penelitian ini dilakukan melalui pengujian eksperimental di laboratorium. Sintesis senyawa yang memiliki aktivitas antioksidan dilakukan dengan pembuatan garam benzenadiazonium klorida. Garam benzenadiazonium selanjutnya direaksikan dengan vanilin pada suhu $0-5{ }^{\circ} \mathrm{C}$. Senyawa hasil sintesis diuji kemurniannya dengan mengukur titik lelehnya. Uji aktivitas antioksidan terhadap DPPH dengan variasi konsentrasi (K) yaitu: 25, 50, 100, 200, dan $500 \mathrm{ppm}$.

\section{Cara Kerja}

Sintesis Senyawa 4-hidroksi-3-metoksi5(fenildiazenil)benzaldehida

Sebanyak $24 \mathrm{mmol}$ anilina $(2,235$ g) anilina dilarutkan dalam campuran 72 mmol $\mathrm{HCl} 37 \% \mathrm{~b} / \mathrm{b}(6 \mathrm{~mL})$ dan $6 \mathrm{~mL}$ akuades dalam gelas beaker $250 \mathrm{~mL}$. Larutan didinginkan dalam penangas es sampai suhu $0-5{ }^{\circ} \mathrm{C}$. Sebanyak $26,4 \mathrm{mmol}$ $\mathrm{NaNO}_{2}(1,822 \mathrm{~g})$ dilarutkan ke dalam $9 \mathrm{~mL}$ akuades dan didinginkan dalam penangas es. Larutan $\mathrm{NaNO}_{2}$ ditambahkan sedikit demi sedikit ke dalam larutan anilina- $\mathrm{HCl}$ sambil diaduk dan suhu dijaga $0-5{ }^{\circ} \mathrm{C}$ sehingga dihasilkan larutan garam benzenadiazonium klorida. Larutan ini selanjutnya didiamkan beberapa menit dengan suhu tetap dijaga $0-5{ }^{\circ} \mathrm{C}$ (Purwono dkk., 2013).

Selanjutnya sebanyak $16 \mathrm{mmol}$ vanilin $(2,434 \mathrm{~g})$ dilarutkan ke dalam 7,5 mL larutan $\mathrm{NaOH} 10 \%(\mathrm{~b} / \mathrm{v})$. Larutan didinginkan dalam penangas es sampai suhu $0-5{ }^{\circ} \mathrm{C}$. Larutan dingin garam benzenadiazonium klorida ditambahkan kedalam larutan natrium vanilat secara perlahan-lahan sambil terus diaduk sampai terbentuk gel. Gel dipisahkan dengan cara ekstraksi menggunakan kloroform sebanyak 3 x $25 \mathrm{~mL}$ dan dinetralkan dengan larutan $\mathrm{NaHCO}_{3}$. Ekstraktan kemudian dikeringkan dengan $\mathrm{Na}_{2} \mathrm{SO}_{4}$ anhidrat. Kloroform diuapkan dengan rotary evaporator dan dikeringkan dalam desikator. Senyawa hasil sintesis diuji kemurniannya dengan mengukur titik lelehnya. Senyawa murni tersebut ditentukan struktur senyawanya dengan spektrometer IR, KG-SM dan ${ }^{1} \mathrm{H}-\mathrm{NMR}$ (Purwono dkk., 2013).

\section{Uji Aktivitas Antioksidan Senyawa 4- hidroksi-3-metoksi-5(fenildiazenil) benzaldehida Menggunakan Metode DPPH}

Cara pembuatan kontrol: Larutan DPPH dengan konsentrasi $0,2 \mathrm{mM}$ diambil sebanyak 2,25 mL, kemudian dimasukkan dalam tabung reaksi, ditambahkan pelarut etanol sebanyak $6,75 \mathrm{~mL}$. Tabung reaksi ditutup dengan tisue, lalu diinkubasi pada suhu $37{ }^{\circ} \mathrm{C}$ selama waktu kestabilan yang telah didapatkan pada tahap sebelumnya. Setelah itu diukur absorbansinya dengan menggunakan UV-Vis pada $\lambda_{\text {maks }}$ yang didapatkan pada tahap sebelumnya.

Masing-masing sampel senyawa 4hidroksi-3-metoksi-5(fenildiazenil)benzaldehida dilarutkan dalam pelarut etanol dengan konsentrasi 10, 25, 50, 100, 200 dan 500 ppm. Kemudian disiapkan lima tabung reaksi untuk masing-masing konsentrasi. Tiap tabung reaksi diisi 
dengan 6,75 $\mathrm{mL}$ larutan sampel dan ditambahkan DPPH 0,2 mM sebanyak 2,25 $\mathrm{mL}$. Setelah itu larutan ditutup dengan tisue dan diinkubasi dengan suhu $37{ }^{\circ} \mathrm{C}$ pada waktu kestabilan yang diperoleh pada proses sebelumnya, kemudian diukur absorbansinya menggunakan spektrofotometer $\mathrm{UV}-\mathrm{V}$ is pada $\lambda_{\text {maks }}$ yang telah didapatkan sebelumnya. Data absorbansinya yang diperoleh dari tiap konsentrasi masing-masing ekstrak dihitung nilai persen (\%) aktivitas antioksidannya. Nilai tersebut diperoleh dengan persamaan:

$$
\begin{aligned}
& \% \text { Aktivitas } \\
& \text { antioksidan }
\end{aligned}=\frac{\text { Abs kontrol }- \text { Abs sampel }}{\text { Absorbansi kontrol }} \times 100 \%
$$

Setelah didapatkan persen (\%) aktivitas antioksidanya, selanjutnya masing-masing sampel dihitung nilai $\mathrm{EC}_{50}$ nya dengan menggunakan persamaan regresi.

\section{HASIL DAN PEMBAHASAN}

\section{Sintesis 4-hidroksi- 3-metoksi- 5(fenildiazenil) benzaldehida}

Senyawa 4-hidroksi-3-metoksi5(fenildiazenil) benzaldehida disintesis melalui modifikasi sintesis dari Purwono dkk. (2013) dengan perbandingan antara garam benzenadiazonium klorida dan vanilin adalah 1,5:1.

Reaksi pembentukan senyawa produk sintesis dimulai dari pembuatan garam benzenadiazonium klorida dari campuran anilina, natrium nitrit dan $\mathrm{HCl}$ pada suhu $0-5{ }^{\circ} \mathrm{C}$. Anilina yang bereaksi dengan asam nitrit dingin dalam larutan $\mathrm{HCl}$ menghasilkan garam benzenadiazonium klorida. Asam nitrit dibuat in situ oleh reaksi natrium nitrit dengan $\mathrm{HCl}$. Garam diazonium dapat reaktif sehingga campuran reaksi harus didinginkan $\left(0-5^{\circ} \mathrm{C}\right)$.

Garam benzenadiazonium klorida yang terbentuk selanjutnya ditambahkan ke dalam natrium vanilat yang berupa campuran vanilin dan $\mathrm{NaOH} 10 \%$ suhu 0 $5{ }^{\circ} \mathrm{C}$. Garam benzenadiazonium klorida bereaksi dengan cincin aromatik yang teraktivasi kuat (natrium vanilat) menghasilkan senyawa Azo. Reaksi substitusi aromatik elektrofilik ini dinamakan penggandengan diazo (diazo coupling), sebab di dalam produknya dua cincin aromatik tergandeng oleh azo atau gugus $-\mathrm{N}=\mathrm{N}-$. Penggandengan para lebih disukai, tetapi jika posisi para dihalangi oleh substituen lain maka penggandengan orto dapat terjadi.

Produk yang dihasilkan berupa padatan berwarna coklat kehitaman dengan rendemen 88,54\% dan titik lebur $100{ }^{\circ} \mathrm{C}$. Titik lebur yang rendah ini dapat diasumsikan bahwa padatan produk sintesis masih mengandung air sehingga mempengaruhi hasil pembacaan titik lebur.

Terdapat tiga tahap mekanisme reaksi pembentukan senyawa 4-hidroksi-3metoksi-5-(fenildiazenil) benzaldehida dari ion benzenadiazonium dan vanilin melalui reaksi kopling diazo. Mekanisme reaksi tahap I adalah reaksi pembentukan ion vanilat dari vanilin menggunakan katalis basa. Mekanisme reaksi tahap II adalah adalah reaksi pengikatan gugus azo $(-\mathrm{N}=\mathrm{N}-$ ) padaion benzenadiazonium dengan ion vanilat. Mekanisme reaksi tahap III adalah reaksi pengikatan intermolekul antara atom $\mathrm{H}$ pada cincin non aromatis dengan atom O karbonil membentuk senyawa 4hidroksi-3-metoksi-5-fenildiazenil) benzaldehida yang aromatis.

Mekanisme reaksi tahap I

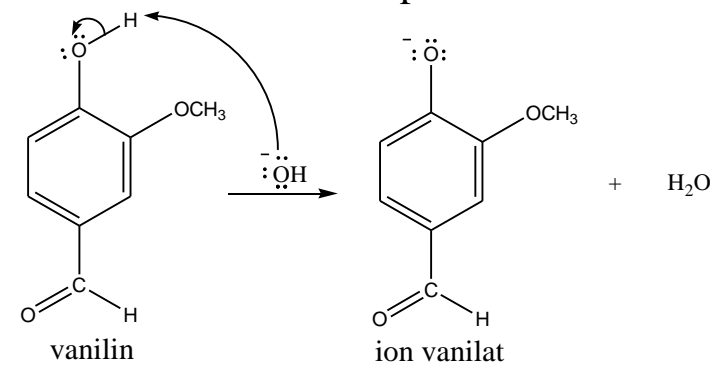




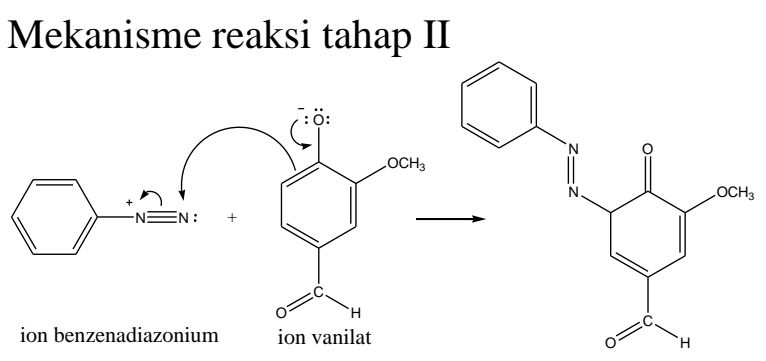

Mekanisme reaksi tahap III

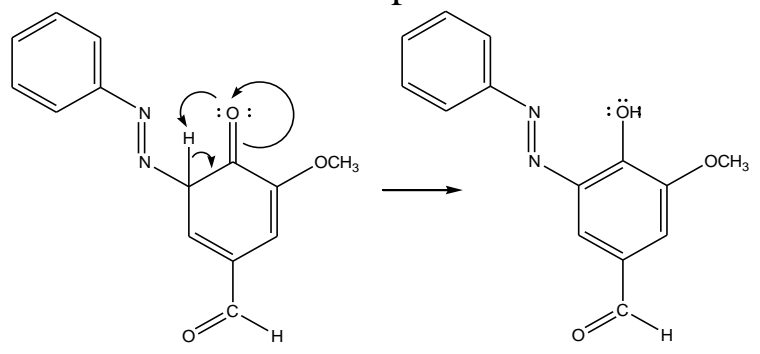

Pada tahap I, Pasangan elektron bebas pada atom oksigen yang bermuatan negatif dari katalis basa menyerang atom hidrogen dari gugus hidroksil pada vanilin membentuk $\mathrm{H}_{2} \mathrm{O}$. Vanilin yang melepaskan $\mathrm{H}^{+}$pada suasana basa membentuk ion vanilat yang teraktivasi kuat. Pada tahap II, Ion vanilat sebagai cincin aromatik menyerang ion benzenadiazonium yang termasuk elektrofili lemah melalui reaksi kopling diazo. Tahap ini menghasilkancincin non aromatis dari ion vanilat yang berikatan dengan gugus azo ($\mathrm{N}=\mathrm{N}-$ ) padaposisi ortoyang masih kosong dari gugus hidroksi. Dan pada tahap III, Pasangan elektron bebas atom $\mathrm{O}$ karbonil mengikat atom hidrogenpada cincin untuk mengembalikan aromatisitas cincin.Ikatan C-H pada cincin putus membentuk ikatan rangkap $(\mathrm{C}=\mathrm{C})$ yang diikuti dengan pembentukan ikatan $\mathrm{C}-\mathrm{OH}$ pada atom $\mathrm{C}$ karbonil.

Keberhasilan sintesis dipantau secara kromatografi lapis tipis (KLT) dengan fase diam pelat silika gel dan pengembang kloroform $5 \mathrm{~mL}$ dengan pembanding vanilin.Plat KLT yang digunakan berukuran 10x4 cm. Penotolan dilakukan sekali. Kromatogram produk sintesis (Gambar 4.2) menunjukkan telah terbentuk senyawa baru yang lebih non polar daripada reaktan.

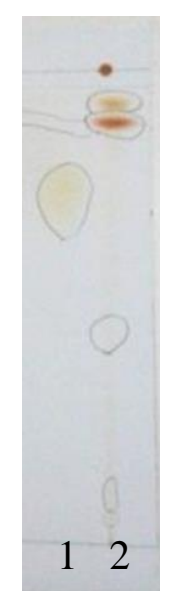

Gambar 2. Kromatogram Kromatografi Lapis Tipis (KLT) dengan fase diam silika gel, pengembang kloroform Vanilin (1) dan Produk sintesis (2).

Berdasarkan kromatogram KLT, terdapat beberapa spot yang menunjukkan adanya sisa reaktan dan produk hasil sintesis. Dua spot berwarna kecoklatan dengan niali Rf berdekatan yang dimungkinkan merupakan produk dari sintesis. Hasil sintesis memiliki Rf yang lebih tinggi atau lebih non polar dibandingkan dengan reaktan. Untuk memastikan dugaan terbentuknya produk dan mengetahui kadarnya dilakukan identifkasi dengan Kromatrografi Gas Spektrofotometer Massa dan diuji aktifitas antioksidannya terhadap DPPH.

\section{Uji Aktivitas Antioksidan Hasil Sintesis Terhadap DPPH}

Uji kuantitatif potensi antioksidan pada penelitian ini dilakukan dengan uji DPPH secara spekrofotometri sinar tampak. Metode ini didasarkan pada perubahan warna radikal DPPH. Perubahan warna tersebut disebabkan oleh reaksi antara radikal bebas DPPH dengan satu atom hidrogen yang dilepaskan senyawa yang terkandung dalam bahan uji untuk membentuk senyawa 1,1-diphenyl-2picrylhydrazin yang berwarna kuning. 
Pada metode ini absorbansi yang diukur adalah absorbansi larutan DPPH sisa yang tidak bereaksi dengan senyawa antioksidan (Josephy, 1997).

Pengujian aktivitas antioksidan ini dilakukan pada variasi konsentrasi 10, 25, 50, 100, 200, dan 500 ppm, selanjutnya diukur serapannya pada panjang gelombang 518,0 nm dengan rentang waktu yang telah didapatkan pada penentuan waktu kestabilan. Pengukuran aktivitas antioksidan pada sampel menggunakan larutan kontrol DPPH 0,2 mM. Larutan DPPH kontrol digunakan untuk memberikan kestabilan pada saat pengukuran aktivitas antioksidan pada sampel (Arindah, 2010). Menurut Molyneux (2003), nilai absorbansi kontrol dapat berkurang dari hari ke hari dikarenakan kehilangan aktivitasnya saat dalam stok larutan DPPH, tetapi nilai absorbansi kontrol tetap dapat memberikan baseline untuk pengukuran saat itu.

Larutan DPPH mengalami perubahan warna setelah dicampur dengan sampel dan diinkubasi. Terjadi perubahan warna dari ungu tua menjadi ungu pudar dan kuning setelah inkubasi 60 menit. Perubahan warna ini menandakan bahwa sampel memiliki kemampuan sebagai antioksidan. Pengurangan intensitas warna yang terjadi berhubungan dengan jumlah elektron DPPH yang menangkap atom hidrogen dari senyawa antioksidan. Pengurangan intensitas warna mengindikasikan peningkatan kemampuan antioksidan untuk menangkap radikal bebas (Prakash, 2001).

Parameter yang digunakan untuk mengetahui potensi antioksidan dalam sampel yaitu persen (\%) aktivitas antioksidan dan nilai $\mathrm{EC}_{50}$. Persen aktivitas antioksidan menunjukkan kemampuan suatu antioksidan dalam menghambat radikal bebas (dalam bentuk \%). Persen aktivitas antioksidan menunjukkan banyaknya atom hidrogen dari senyawa antioksidan yang menangkap radikal
DPPH sehingga tereduksi menjadi DPPH$\mathrm{H}(1,1-$ diphenyl-2-picrylhydrazyn) (Rahayu et al., 2010). Persen (\%) aktivitas antioksidan dari sampel hasil sintesis ditunjukkan dalam Tabel 1.

Tabel 1 Persen aktivitas antioksidan sampel hasil sintesis

\begin{tabular}{lll}
\hline No & $\begin{array}{c}\text { Konsentrasi } \\
\text { sampel (ppm) }\end{array}$ & $\begin{array}{c}\text { \% aktivitas } \\
\text { antioksidan }\end{array}$ \\
\hline 1 & 10 & 1.0165 \\
2 & 25 & 6.2571 \\
3 & 50 & 11.8365 \\
4 & 100 & 19.8554 \\
5 & 200 & 26.1577 \\
6 & 500 & 28.4391 \\
\hline
\end{tabular}

Hasil pengukuran persen aktivitas antioksidan pada Tabel 4.2 menunjukkan bahwa senyawa hasil sintesis dapat berpotensi sebagai antioksidan. Parameter selanjutnya untuk mengetahui potensi antioksidan dalam sampel adalah nilai $\mathrm{EC}_{50}$ (effective concentration). $\mathrm{EC}_{50}$ dapat didefinisikan sebagai konsentrasi larutan sampel yang akan menyebabkan reduksi terhadap aktivitas DPPH sebesar $50 \%$. Semakin kecil nilai $\mathrm{EC}_{50}$ maka aktivitas antioksidannya semakin tinggi (Molyneux, 2004). Suatu senyawa dikatakan sebagai antioksidan sangat kuat jika nilai $\mathrm{EC}_{50}$ bernilai kurang dari $50 \mathrm{ppm}$, kuat jika bernilai $50-100$ ppm, sedang jika bernilai 100 - 150 ppm, dan lemah jika bernilai 150 - 200 ppm (Putra, 2012).

Berdasarkan hasil analisa diperoleh nilai $\mathrm{EC}_{50}$ senyawa hasil sintesis adalah 800,26 ppm. Aktivitas antioksidan sampel tergolong sangat lemah. Hal ini dimungkinkan karena sampel masih berupa campuran dan belum merupakan produk murni. Oleh karena itu, perlu dilakukan optimasi reaksi sintesis dan pemurnian senyawa hasil sintesis. 


\section{KESIMPULAN}

Reaksi kopling diazo antara senyawa vanilin dengan ion benzenadiazonium menghasilkan senyawa 4-hidroksi-3-metoksi-5-

(fenildiazenil)benzaldehida yang esih belum murni. Senyawa produk sintesis berupa padatan berwarna coklat kehitaman dengan rendemen $88,54 \%$ dan titik lebur $100^{\circ} \mathrm{C}$.

Senyawa hasil sintesis memiliki aktivitas antioksidan. Aktivitas antioksidan senyawa hasil sintesis masih tergolong sangat lemah karena masih berupa campuran dan masih memerlukan proses optimalisasi dan pemisahan.

\section{DAFTAR PUSTAKA}

Arindah, D. 2010. Fraksinasi dan Identifikasi Golongan Senyawa Antioksidan pada Daging Buah Pepino (Solonum Muricatum aiton) yang Berpotensi sebagai Antioksidan. Skripsi Tidak Diterbitkan. Malang: Jurusan Kimia Fakultas Sains dan Teknologi UIN Maulana Malik Ibrahim Malang.

Josephy, P.D. 1997. Molecular Toxicology. New York: Oxford University Press.

Molyneux, P.. 2003. The Use of The Stable Free Radical Diphenylpicrylhydrazyl (DPPH), for Estimating Antioxidant Activity. Science and Technology, XXVI (2) : 211-219.

Naik, N., Kumar, V.H., Dias, S.M., and Swami, R.J. 2013. Novel 4-Methoxy2-Acetyl Benzofuran Based Chalcones: A New Perceptivity Into Their Antioxidant Potentials. International Journal of Pharmacy and Pharmaceutical Sciences. Vol 5, Issue 1, page $242-247$.

Prakash, A.. 2001. Antioxidant Activity. Analytical Chemistry Medallion Laboratories: Analytical Progress, X (2).

Purwono, B., Anwar, C., and Hanapi, A., 2013, Syntheses of Azo-imine
Derivatives from Vanillin as an Acid Base Indicator, Indo. J. Chem., 13, 1, 1-6.

Purwono, B., and Mahardiani, C., 2009, Synthesis of Azo Compounds Derivative from Eugenol and Its Application as a Titration Indicator, Indo. J. Chem., 9, 1, 95-98.

Putra, D.A.D.. 2012. Identifikasi Komponen Kimia Minyak Atsiri Daun Bunga Tahi Ayam (Tagetes Erecta L.) serta Uji Aktivitas Antibakteri dan Antioksidan. Skripsi Tidak Diterbitkan. Universitas Sumatera Utara.

Rahayu, D.S, dkk. 2010. Penentuan Aktivitas Antioksidan dari Ekstrak Etanol Daun Ketapang (Terminalia catappa $\mathrm{L}$ ) dengan Metode 1,1 difenil 2 Pikrilhidrazil (DPPH). Semarang: Jurusan Kimia FMIPA Universitas Diponegoro.

Shihab, M.Q. 2002. Tafsir Al-Mishbah: Pesan, Kesan dan Keserasian AlQuran Volume 7. Jakarta: Lentera Hati.

Shyamala, B. N., Naidu, M., Sulochanamma, G. S., dan Srivinas, P. 2007. Studies on the antioxidant activities of natural vanilla extract and its constituent compounds through in vitro models. Journal of Agricultural and Food Chemistry (55) 7738-7743. 